\title{
Stereological Estimate of the Length of Microvessels and the Number, Proliferation and Apoptosis of Endothelial Cells in Prostate Cancer
}

\author{
Luis Santamaría,*, Ildefonso Ingelmo ${ }^{2}$, Jesús Ruiz ${ }^{3}$, Fernando Teba ${ }^{4}$, Luis M. Herranz ${ }^{4}$, \\ Guillermo Montalbán ${ }^{1}$, Rocío Martín ${ }^{5}$, Javier Codesal ${ }^{1}$, José M. Pozuelo ${ }^{6}$, Rosario Rodríguez ${ }^{6}$ \\ and Riánsares Arriazu ${ }^{6}$
}

\begin{abstract}
${ }^{I}$ Department of Anatomy, Histology, and Neuroscience. School of Medicine, Autonomous University of Madrid, Madrid, Spain; ${ }^{2}$ Department of Anesthesiology. Hospital Ramón y Cajal, Madrid, Spain; ${ }^{3}$ Department of Anesthesiology. Hospital Primero de Octubre, Madrid, Spain; ${ }^{4}$ Department of Surgery (Urology). Hospital de La Princesa, School of Medicine, Autonomous University of Madrid, Spain; ${ }^{5}$ Department of Pathology. Hospital N. Sr. Sonsoles, Ávila, Spain and ${ }^{6}$ Department of Histology, School of Medicine, San Pablo University, CEU, Madrid, Spain
\end{abstract}

\begin{abstract}
Abnormal angiogenesis is a critical feature of many diseases, including cancers and their precursors. Although the association between prostate carcinogenesis and changes in microvascular architecture is well known, these changes are not well-documented from a quantitative point of view. The present work deals with stereological estimates of the number of quiescent and proliferative endothelial cells, and microvessel length in normal and prostate cancer tissues. Unbiased stereological measurements of numerical densities of proliferating cell nuclear antigen immunostained cells, nonproliferating endothelial cells, caspase 3 immunoreactive endothelial cells, and relative length (length density) of microvessels, were performed in control and cancer specimens. There were no changes in either proliferation or apoptosis in carcinoma endothelial cells. A decrease of endothelial cell density, together with an increase of microvessel length density, were detected in prostate cancer specimens.

Therefore, the following conclusions can be drawn: a) The increase of angiogenetic activity in prostate carcinogenesis leads to an increment of the microvascular length; b) The amount of endothelial cells per vascular length decreases in prostate cancer; c) There is no decrease of endothelial apoptosis in cancer microvessels. d) The increase of the length density of microvessels in prostate cancer is not directly associated to an enhancement of the endothelial proliferation; and e) The blood supply of epithelium was similar in both cancerous and normal prostate.
\end{abstract}

Key Words: Angiogenesis, prostate cancer, endothelium, microvascular length, cell proliferation, endothelial apoptosis, stereology.

\section{INTRODUCTION}

The scientific world is currently dedicating attention to the prostate because of the increase of incidence and prevalence of prostate pathology, either benign or malignant. There are a great number of biological factors intervening in the establishment, development, and progression of malignant proliferative prostatic pathology [1]. A relevant factor is vascularization, given the influence that the microvascular environment exerts on the growth of prostatic carcinoma [2]. The number of cells in a certain cellular population is the end point resulting from the equilibrium between proliferation and programmed death. The endothelium is the main component of microvessels and plays an important role in the establishment of the size and architecture of the microvascular bed [3]. It seems interesting to quantitate the final amount of endothelial cells and their rates of proliferation and apoptosis, in order to obtain better knowledge of the

\footnotetext{
*Address correspondence to this author at the Department of Anatomy, Histology, and Neuroscience, School of Medicine, Autonomous University of Madrid, C/Arzobispo Morcillo 2, 28029-Madrid, Spain; Tel: 34-
} 914975367; Fax: 34-914975353; E-mail: luis.santamaria@uam.es dynamism of this cell population in both normal and tumoral conditions.

Caspases are fundamental components of the mammalian apoptotic machinery. Caspase 3 is a prototypical enzyme that becomes activated in a wide variety of tissues during apoptosis [4]. On the other hand, there is evidence of a loss of caspase 3 protein expression in prostate cancer [5]. The quantification of immunoexpression of caspase 3 might constitute a reliable method for measuring apoptotic activity in prostate cancer.

Alternately, angiogenesis is basically defined as the process leading to the formation of new blood vessels and is essential for normal growth and development [6]. In normal adults, active angiogenesis occurs infrequently [3]. Abnormal angiogenesis is a critical feature of many diseases, including cancers and their precursors $[7,8]$.

Focusing on the prostate, there are a number of reports concerning neovascularity and invasive cancer which, on the whole, suggest a link between increased vascular density and an aggressive tumor phenotype [9-12]. Scarce rigorous stereological assessment has been performed regarding this 
matter [13], as most of the studies concerning quantification of microvessels employ microvessel density (MVD), or counting of the number of microvessel profiles [13-16]. Currently, MVD is not consistently defined and it seemed interesting to evaluate microvascularity by unbiased stereologic tools, such as length density $\left(\mathrm{L}_{\mathrm{V}}\right)$ (defined as the length of microvessels per unit of volume of tissue) [17], to obtain more accurate and rigorous measurements.

The present study deals with the stereologic estimation of $\mathrm{L}_{\mathrm{V}}$ for microvessels in cancer and normal prostate specimens, to confirm the hypothesis that the increase of angiogenetic activity in prostate carcinogenesis leads to an increment of microvascular length [18], and to ascertain if this increment is related to an enhancement of endothelial proliferation in tumoral microvessels [19]. Proliferating and non-proliferating endothelial cells, as well as apoptotic endothelial cells, were counted in order to correlate the size of the microvascular bed with the growth of the endothelial population in normal and cancerous prostate.

\section{MATERIALS AND METHODOLOGY}

\section{Materials}

Thirty prostate specimens were collected at La Princesa Hospital (Madrid, Spain). The first 15 (CTR group) were from healthy subjects without endocrine or reproductive pathology, deceased in traffic accidents, and eligible as donors for transplant: adults, age (mean \pm SD): $33 \pm 8.5$; range: 20 47 years. The remaining 15 were surgical specimens (radical prostatectomy) from patients diagnosed with prostate carcinoma (CA group): age (mean $\pm \mathrm{SD}$ ): $70 \pm 10$; range: 56 to 85 years. In all these cases, the diagnostic of carcinoma was previously confirmed by histopathology. Eleven of the cancer cases had a Gleason score of $7(3+4)$, and the rest had a Gleason score of $6(3+3)$. The CA cases were without prior neoadjuvant hormonal therapy.

All ethical requirements were carried out in order to obtain the prostatic tissue either at the moment of the multiorganic extraction for transplant (CTR group) or at surgery (CA group). Immediately after extraction, the specimens were weighed and their fresh volume was obtained by water displacement. All the specimens were fixed in $10 \%$ paraformaldehyde in PBS, $\mathrm{pH} 7.4$, for 24 hrs.

\section{Sampling Protocol}

After fixation, the specimens from both the CTR and CA groups were thoroughly sectioned into 2-mm-thick slices, performed by isotropic uniform random sampling (IUR sections) [20], to assure an isotropic encounter between the tissue and the probe for estimation of the microvessel length [21].

\section{Immunohistochemistry}

All the IUR sampled slices were then processed by paraffin embedding. The paraffin blocks were exhaustively sectioned into five- $\mu \mathrm{m}$-thick sections (for routine hematoxylineosine), alternating with $10-\mu \mathrm{m}$-thick sections (for stereological measurements). Two types of double immunostainings were performed in order to (a) visualize the endothelial nuclei immunoreactive to proliferating cell nuclear antigen
(PCNA) together with the microvascular structure immunoreactive to Von Willebrand factor (Factor VIII related antigen) [13], and b) to show simultaneously the endothelial cells immunostained to caspase 3 and the microvessels immunostained to Factor VIII. At least ten randomly selected slides per specimen groups (five for PCNA plus Factor VIII, and five for caspase 3 plus Factor VIII) were immunostained in the CTR and CA groups. Deparaffinized and rehydrated tissue sections were treated for 30 min with hydrogen peroxide $0.3 \%$ in phosphate-buffered saline (PBS) $\mathrm{pH} 7.4$ to block endogenous peroxidase. Mouse monoclonal and rabbit polyclonal antibodies were used as primary antibodies.

To detect PCNA immunoreactivity, sections were incubated with a monoclonal anti-PCNA antibody (Biomeda, Foster City, CA, USA) diluted at 1:200. To detect caspase 3 immunoreactivity, a monoclonal anti-caspase 3 antibody (Cell Signaling Technology Inc., Beverly, MA, USA) diluted at 1:50 was employed. Pretreatment of sections by heat in citrate buffer $\mathrm{pH} 6.0$ (using a pressure cooker) [22] was performed to enhance both immunostainings. The primary antisera were diluted in PBS pH 7.4 containing $1 \%$ bovine serum albumin (BSA) plus $0.1 \%$ sodium azide. Incubation with primary antisera was performed overnight at $4^{\circ} \mathrm{C}$.

The second antibody employed was a biotin-caproyl-antimouse immunoglobulin (Biomeda), diluted at 1:400 in PBS containing $1 \%$ BSA without sodium azide, and incubated for $30 \mathrm{~min}$ at room temperature. Thereafter, sections were incubated with a streptavidin-biotin-peroxidase complex (Biomeda). The immunostaining reaction product (in brown) was developed using $0.1 \mathrm{~g}$ diaminobenzidine (DAB) $\left(3,3^{\prime}, 4,4^{\prime}\right.$ Tetraminobiphenyl, Sigma, St Louis, USA) in $200 \mathrm{~mL}$ of PBS, plus $40 \mu \mathrm{L}$ hydrogen peroxide.

Afterwards, the sections immunostained to PCNA and to caspase 3 were again processed for immunostaining to Factor VIII. A polyclonal antibody (Sigma), diluted at 1:1000 in PBS pH 7.4 containing 1\% bovine serum albumin (BSA) plus $0.1 \%$ sodium azide was employed. The second antibody used was a biotin-caproyl-anti-rabbit immunoglobulin (Biomeda). Thereafter, sections were incubated with a streptavidin-alkaline phosphatase complex (Biomeda). The immunostaining reaction product (in blue) was developed using the BCIP/NBT substrate kit (Zymed, San Francisco, CA, USA). The antisera diluents and incubation protocols for immunostaining to Factor VIII were identical to protocol for PCNA or caspase 3 .

After immunoreactions, sections were counter-stained with Harris hematoxylin. All slides were dehydrated in ethanol and mounted in a synthetic resin (Depex, Serva, Heidelberg, Germany). The specificity of the immunohistochemical procedures was checked by incubation of sections with nonimmune serum instead of the primary antibodies.

\section{Quantitative Methods}

The numerical density $\left(\mathrm{N}_{\mathrm{V}}\right)$ of endothelial cells (cell number per unit of volume of reference space) was estimated for both PCNA immunoreactive ( $\mathrm{N}_{\mathrm{V}}$ PCNA positive) and PCNA negative nuclei ( $\mathrm{N}_{\mathrm{V}}$ PCNA negative), employing the optical disector, an unbiased stereological method, [23] using the Cast-Grid program (Stereology Software Package, Silkeborg, Denmark). 
In the case of immunostaining for caspase 3 , the $\mathrm{N}_{\mathrm{V}}$ of both endothelial cells, with and without cytoplasmic immunoreactivity for caspase 3, was estimated with the same procedure as that employed in PCNA sections. The counting unit was the nucleus of either caspase 3 positive or negative cells. The reference space for estimating the numerical densities was that occupied by the stroma of the prostate.

In order to measure the volume of the reference space, the number of disector frames with the upper-right corner hitting the stromal tissue (n) was registered. The total volume of the reference space was $\Sigma$ Vdis $=n \cdot V$ dis. Vdis $=$ area of the disector frame $\left(1,482 \mu \mathrm{m}^{2}\right)$, multiplied by the distance between the two focal planes chosen for determining the disector volume in the tissue section $(5 \mu \mathrm{m})$. This distance was measured by means of a microcator (Heidenhain: Traunreut, Germany) connected to the $\mathrm{Z}$ displacement of the microscope stage.

As the material was embedded in paraffin, it showed significant shrinkage. Therefore, a shrinkage factor (FrV), i.e., the ratio between fresh volume, calculated by water displacement and the volume after paraffin embedding, measured by the Cavalieri estimator [21] $(\mathrm{FrV}=1.21)$, was obtained and introduced into the formula for calculation of $\mathrm{N}_{\mathrm{V}}$. The formula then employed to estimate $\mathrm{N}_{\mathrm{V}}$ was:

$\mathrm{N}_{\mathrm{V}}=\Sigma \mathrm{Q}_{\mathrm{d}}{ }^{-} / \Sigma \mathrm{Vdis} \cdot \mathrm{FrV}$; where $\mathrm{Q}_{\mathrm{d}}{ }^{-}$was the number of nuclei eligible for counting, according to the Sterio convention [23].

The total $\mathrm{N}_{\mathrm{V}}$ of endothelial cells was calculated as $\mathrm{N}_{\mathrm{V}}$ total = NV (PCNA negative + PCNA positive). The labeling index of PCNA (LIpcna) for endothelial cells was expressed as the ratio $\mathrm{N}_{\mathrm{V}}$ PCNA positive / $\mathrm{N}_{\mathrm{V}}$ total. The labeling index of caspase 3 (LIcaspase 3) for endothelial cells was expressed as the ratio $\mathrm{N}_{\mathrm{V}}$ caspase 3 positive / $\mathrm{N}_{\mathrm{V}}$ total.

For all practical purposes, biological microstructures such as capillaries, tubules and axons can be regarded as linear features, whose most important stereological attribute is their length density $\left(\mathrm{L}_{V}\right)$. The $\mathrm{L}_{\mathrm{V}}$ of microvessels, i.e., length of microvessels per unit of volume of prostate tissue, was evaluated in both the CTR and CA groups. Moreover, in order to assure that the measurements were not biased by age, $\mathrm{L}_{\mathrm{V}}$ estimates were also performed in prostate areas from the CA group that were carcinoma-free (peri-tumoral zone: PTZ) and compared with those obtained for the CTR group. The stromal compartment was considered a reference space. The vascular profiles immunostained to Factor VIII, eligible for counting, were those sampled by the disector frame and fulfilling the Sterio convention. The $\mathrm{L}_{\mathrm{V}}$ of microvessels was calculated by the formula:

$\mathrm{L}_{\mathrm{V}}=\left(2 \times \sum \mathrm{Q}^{-}\right) / \sum \mathrm{A} \cdot \mathrm{FrA}$, where $\mathrm{Q}^{-}=$number of eligible immunopositive vascular profiles and $\sum \mathrm{A}=$ stromal area sampled, i.e., area of disector frame $\left(1,482 \mu \mathrm{m}^{2}\right)$, multiplied by the number of selected frames (those with the upper-right corner hitting the stromal tissue). In addition, the total number of frames superimposed onto the fields was also registered in order to obtain the total area (stroma plus epithelium).

An areal shrinkage factor was introduced in the denominator of the formula for calculation of $\mathrm{L}_{\mathrm{V}}$. This factor (FrA) was obtained according to the expression FrA $=$ FrV / FrL, where FrL was the linear shrinkage factor, ie., the ratio between a linear element measured in the fresh tissue and a linear element estimated on a section from paraffin embedded material, FrA $=1.18$.

Vascular length density with respect to epithelial volume $\left(\mathrm{L}_{\mathrm{epV}}\right)$ was also considered. This parameter was calculated by the formula:

$\mathrm{L}_{\mathrm{epV}}=\left(2 \times \sum \mathrm{Q}^{-}\right) / \sum \mathrm{Aep} \cdot \mathrm{FrA}$, where $\mathrm{Q}^{-}=$number of immunopositive vascular profiles and $\sum$ Aep = epithelial area sampled, that is, equal to total area - stromal area.

Furthermore, the number of endothelial cells per millimeter of length of microvessel $\left(\mathrm{N}_{\mathrm{L}}\right)$ was calculated to total endothelial nuclei: $\mathrm{N}_{\mathrm{L}}=\mathrm{N}_{\mathrm{V}}$ total (endothelium) / $\mathrm{L}_{\mathrm{V}}$ microvessels.

A parameter derived from $\mathrm{L}_{\mathrm{V}}$, average microvessel diameter (AMD), was also calculated by the formula:

$$
\mathrm{AMD}=2 \cdot 10^{3} \sqrt{\frac{\mathrm{V}_{\mathrm{V}} \text { vasc }}{\mathrm{V}_{\mathrm{v}} \text { stroma } \bullet \pi \bullet \mathrm{L}_{\mathbf{V}}}}
$$

where $V_{V}$ vasc is the volume fraction occupied by the microvessels, and $V_{V}$ stroma, the volume fraction occupied by the prostate stroma. AMD was expressed in $\mu \mathrm{m}$. Both $\mathrm{V}_{\mathrm{V}}$ vasc and $V_{V}$ stroma were calculated, counting the points hitting either the vascular, stromal or reference area, (the stroma for $\mathrm{V}_{\mathrm{V}}$ vasc, and the total tissue for $\mathrm{V}_{\mathrm{V}}$ stroma), using the CAST-GRID program.

For each parameter, the mean \pm SEM was calculated in each group. The differences between the CTR and CA groups and between the CTR and PTZ were analyzed using the Student's t test $(\mathrm{p}<0.05)$.

The quantitative parameters (total $\mathrm{N}_{\mathrm{V}}$ of endothelial cells, $\mathrm{N}_{\mathrm{V}}$ PCNA- positive endothelial cells, $\mathrm{N}_{\mathrm{V}}$ caspase 3- positive endothelial cells, $\mathrm{V}_{\mathrm{V}} \mathrm{vasc}$, and $\mathrm{V}_{\mathrm{V}}$ stroma) employed as intermediate estimates to obtain the final parameters (LIpcna, LIcaspase 3, $\mathrm{N}_{\mathrm{L}}$ of endothelial cells, and AMD) are shown in Table 1. Only $\mathrm{N}_{\mathrm{L}}$, LIpcna, LIcaspase $3, \mathrm{~L}_{\mathrm{V}}, \mathrm{L}_{\mathrm{epV}}$, and AMD are shown and analyzed.

\section{RESULTS}

Microvessels immunostained to Factor VIII were observed in both the CTR and CA specimens (Fig. 1a-d). More capillaries were apparently seen in CA cases than in CTR specimens, but the amount of capillary profiles touching the basal membrane of the acini was less in CA than in CTR (Fig. 1c,d). However, a similar amount of endothelial nuclei immunoreactive to PCNA was detected in the two groups of study (Fig. 1b,c). In the CTR group, the epithelial nuclei immunostained to PCNA were seen preferently at the basal compartment of the glands (Fig. 1 a,b), whereas the epithelial nuclei immunoreactive to PCNA from the CA group had no preferential localization in the tumoral epithelium (Fig. 1c,d).

In both the CTR and CA groups, caspase 3 immunoreactivity was evidenced in the cytoplasm of epithelial cells (Fig. 2). Moreover, caspase 3 immunostaining was detected in some endothelial cells in both normal and cancer specimens (Fig. 2). 
Table 1. Quantitative Intermediate Measurements

\begin{tabular}{|c|c|c|c|c|c|c|c|c|c|c|c|}
\hline & \# Cases & $\begin{array}{c}\text { \# Total } \\
\text { Disectors }\end{array}$ & $\begin{array}{l}\text { \# Stromal } \\
\text { Disectors }\end{array}$ & $\begin{array}{l}\text { \# Epithelial } \\
\text { Disectors }\end{array}$ & $\begin{array}{c}\text { Epithelial } \\
\text { Area }\left(\mu \mathrm{m}^{2}\right)\end{array}$ & $\begin{array}{c}\text { Stromal } \\
\text { Area }\left(\mu \mathrm{m}^{2}\right)\end{array}$ & $\begin{array}{c}\mathbf{V}_{\mathrm{V}} \\
\text { Stroma }\end{array}$ & $\begin{array}{c}\mathbf{V}_{\mathbf{v}} \\
\text { Vasc }\end{array}$ & $\begin{array}{c}\mathbf{N}_{\mathrm{V}} \text { Total } \\
(\mathbf{x 1 0})\end{array}$ & $\begin{array}{c}\mathrm{N}_{\mathrm{V}} \text { Pcna }+ \\
\left(\mathbf{x 1 0}^{3}\right)\end{array}$ & $\begin{array}{c}\mathbf{N}_{\mathrm{V}} \text { Caspase } 3+ \\
\left(\mathbf{x 1 0 ^ { 3 } )}\right.\end{array}$ \\
\hline CA & 15 & 100 & 67 & 33 & 49,000 & 99,300 & 0.67 & 0.026 & 73 & 20 & 7 \\
\hline
\end{tabular}

Measurements employed to obtain the parameters analyzed in both controls (CTR) and prostate cancer (CA) specimens. \# total disectors: Average number of disectors sampled per case; \# stromal disectors: Average number of disectors per case with the upper-right corner hitting the stromal tissue; \#epithelial disectors: Average number of disectors per case with the upper-right corner hitting the epithelium. Epithelial area $\left(\mu \mathrm{m}^{2}\right)$ : result of multiplying the \# epithelial disectors by $1,482 \mu \mathrm{m}^{2}\left(\operatorname{area}\right.$ of the disector frame). Stromal area $\left(\mu \mathrm{m}^{2}\right)$ : result of multiplying the \# stromal disectors by $1,482 \mu \mathrm{m}^{2}$ (area of the disector frame). $\mathrm{V}_{\mathrm{V}}$ stroma: volume fraction occupied by the stroma related to all the prostate tissue. $\mathrm{V}_{\mathrm{V}}$ vasc: volume fraction occupied by the microvessels related to all the prostate tissue. $\mathrm{N}_{\mathrm{V}}$ total: total number of endothelial cells per $\mathrm{mm}^{3}$ of prostate stroma (x10 $0^{3}$ ). $\mathrm{N}_{\mathrm{V}}$ pcna+: number of PCNApositive endothelial cells per $\mathrm{mm}^{3}$ of prostate stroma $\left(\times 10^{3}\right) . \mathrm{N}_{\mathrm{V}}$ caspase $3+$ : number of caspase 3 positive endothelial cells per mm $\mathrm{m}^{3}$ of prostate stroma $\left(\mathrm{x} 10^{3}\right)$.

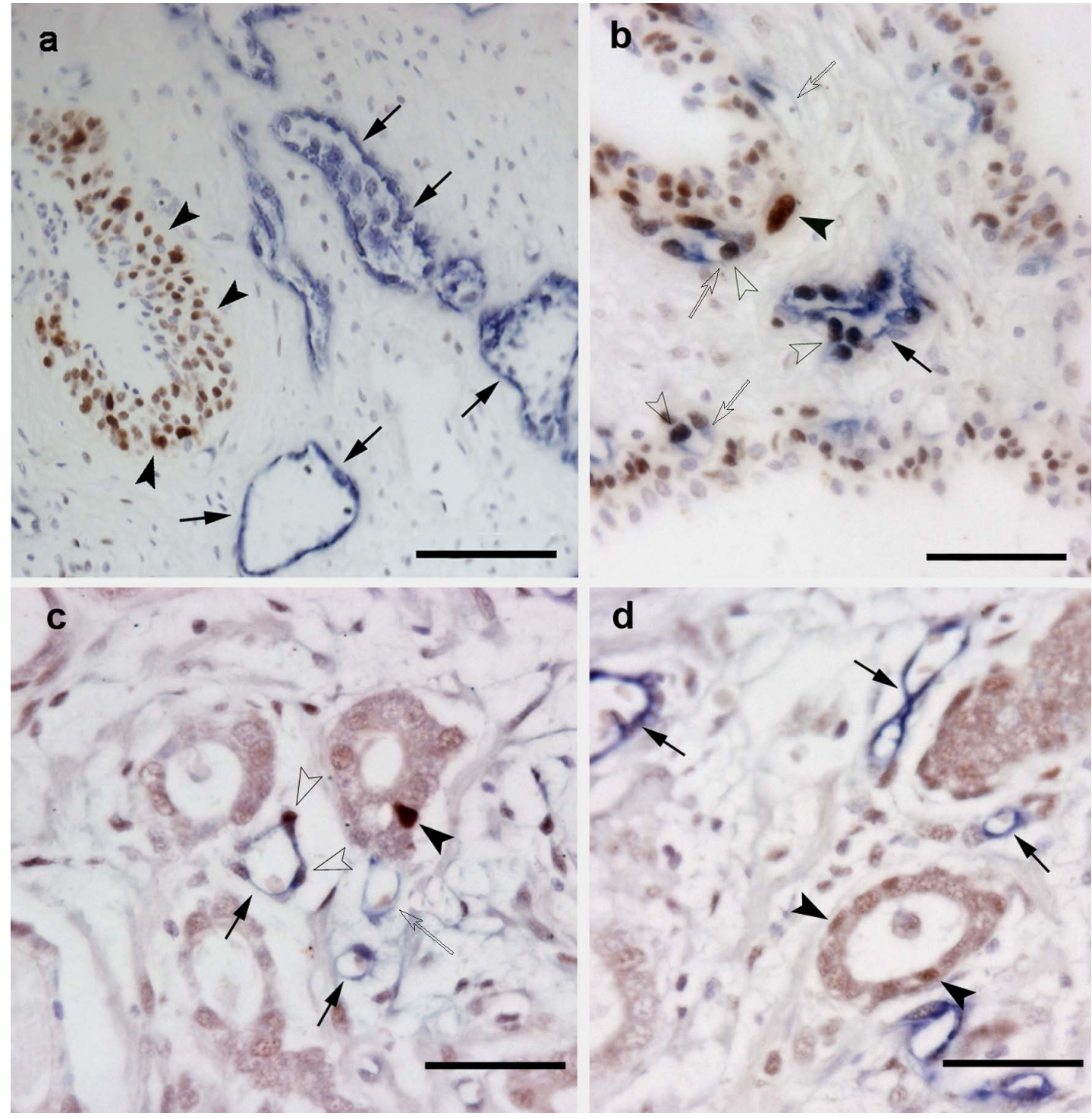

Fig. (1). Double immunostaining to PCNA and Factor VIII. a) Normal prostate (CTR group): a periurethral duct is seen with epithelial nuclei immunoreactive to PCNA, predominantly at basal level (arrowheads). Several microvessels immunoreactive to Factor VIII (arrows) are also seen. Calibration bar: $25 \mu \mathrm{m}$. b) Normal prostate. The epithelial lining of a prostatic acinus shows abundant basal nuclei immunostained to PCNA (black arrowheads). Abundant touching capillaries, immunoreactive to Factor VIII, are seen around the acini (empty arrows). A microvessel not in contact with the acini (black arrow) is also seen. All the microvessels show some endothelial nuclei immunoreactive to PCNA (empty arrowheads). Calibration bar: $20 \mu \mathrm{m}$. c) Prostate carcinoma (CA group). A nucleus immunoreactive to PCNA (black arrowhead) was detected in the epithelial lining of a tumor acinus. Several microvessels immunostained to Factor VIII (empty arrows) are also seen: only one is touching an acinus (empty arrows). Some PCNA immunostained endothelial nuclei (empty arrowheads) are observed. Calibration bar: $12 \mu \mathrm{m}$. d) Epithelial nuclei immunoreactive to PCNA (black arrowheads) were observed in an image from prostate cancer. Several microvessels immunostained to Factor VIII, not touching the acini, are detected (black arrows). Calibration bar: $12 \mu \mathrm{m}$. 

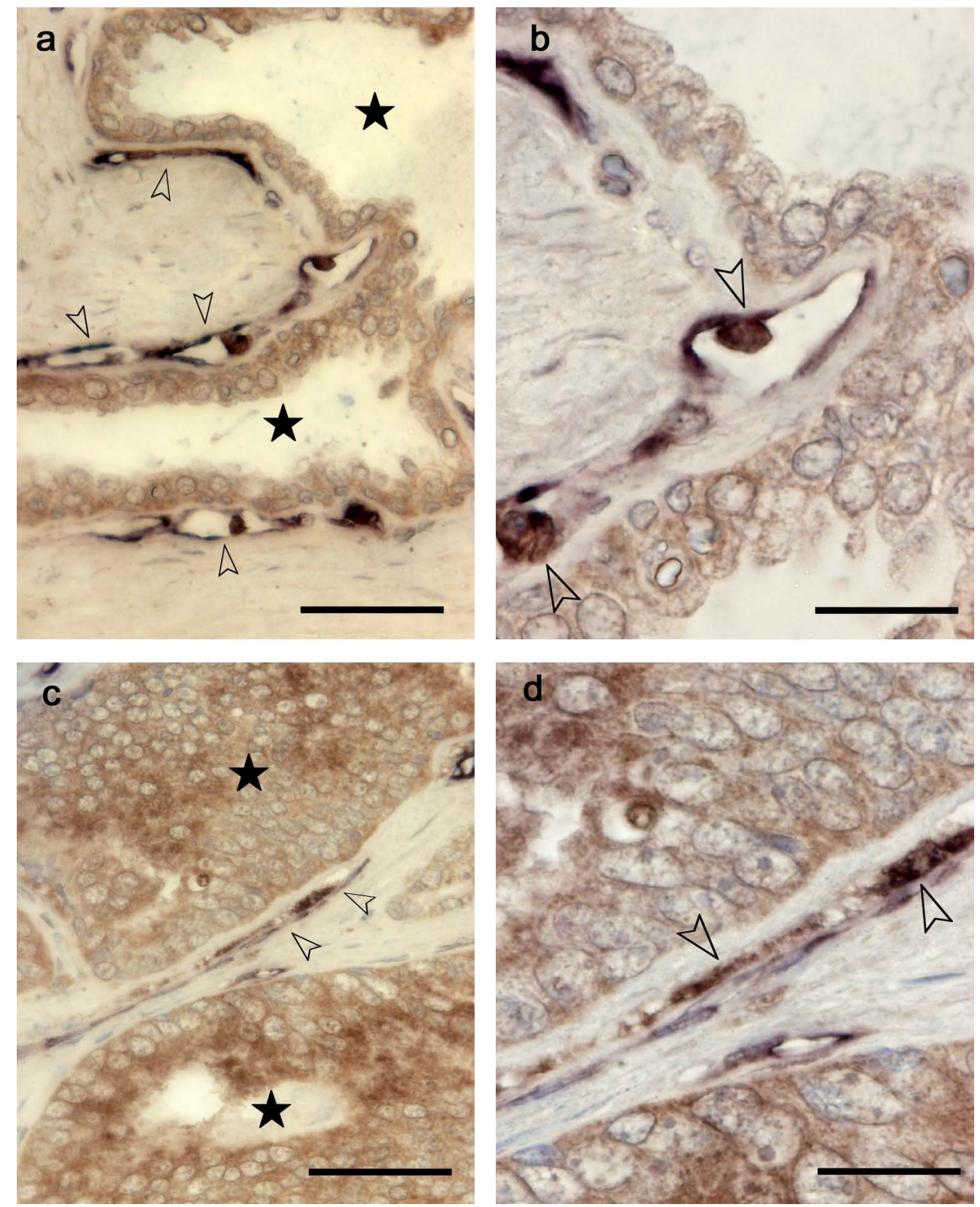

Fig. (2). Double immunostaining to caspase 3 and Factor VIII. a) Normal prostate (CTR group): a prostate acinus (stars) is seen with epithelial immunoreactivity to caspase 3. Several microvessels immunoreactive to Factor VIII (arrowheads) are seen surrounding the acinus. Calibration bar: $50 \mu \mathrm{m}$. b) More details from image a: Some endothelial cells show cytoplasmic immunoreactivity to caspase 3 (arrowheads). Calibration bar: $25 \mu \mathrm{m}$. c) Prostate carcinoma (CA group). The tumor epithelium shows caspase 3 immunostaining (stars). Microvessels immunostained to Factor VIII (arrowheads) are also seen. Calibration bar: $50 \mu \mathrm{m}$. d) More details from image b: Some endothelial cells show granular cytoplasmic immunoreactivity to caspase 3 (arrowheads). Calibration bar: $25 \mu \mathrm{m}$.

Both PCNA and the caspase 3 labeling indices (Lipcna, LIcaspase 3) did not differ significantly between the CTR and CA groups (Table 2), whereas the numerical density of endothelial cells per unit of microvessel length $\left(\mathrm{N}_{\mathrm{L}}\right)$ decreased significantly in the CA group in comparison with the CTR group (Table 2). The density of microvessel length $\left(\mathrm{L}_{\mathrm{V}}\right)$ was significantly increased in the CA group when compared with the CTR group (Table 2). The density of microvessel length with respect to the epithelial volume $\left(\mathrm{L}_{\mathrm{epV}}\right)$ and the average microvessel diameter (AMD) did not differ significantly between the CTR and CA groups (Table 2 ). $\mathrm{L}_{\mathrm{V}}$ did not show significant differences between CTR and PTZ (Fig. 3).

\section{DISCUSSION}

There is a remarkable increase in the relative length of cancer microvessels in comparison with the prostatic capillaries of the CTR group, which is in agreement with the findings of other authors [17] and might be related to the increase of angiogenesis in both cancer and preinvasive lesions indicated by several others $[2,9,12,18,24,25]$. There were no significant differences in microvessel length density between young controls (CTR) and the carcinoma-free tissue from the cancer group (CA), i.e., controls of the same age as CA specimens, which excludes a possible age-dependent bias in the selection of young specimens as controls. These 
Table 2. Comparison between the Quantitative Parameters Analyzed

\begin{tabular}{|c|c|c|c|c|}
\hline & CTR & CA & p & Significance \\
\hline \hline LI pcna & $0.22 \pm 0.02$ & $0.28 \pm 0.04$ & 0.256 & NS \\
\hline $\mathbf{L I}$ caspase 3 & $0.066 \pm 0.014$ & $0.093 \pm 0.022$ & 0.343 & NS \\
\hline $\mathbf{N}_{\mathbf{L}}\left(\mathbf{x 1 0}^{\mathbf{3}}\right)$ & $0.52 \pm 0.09$ & $0.30 \pm 0.05$ & 0.046 & $\mathrm{~S}$ \\
\hline $\mathbf{L}_{\mathbf{V}}\left(\mathbf{m m}^{-\mathbf{2}}\right)$ & $103 \pm 15$ & $290 \pm 61$ & 0.0001 & $\mathrm{NS}$ \\
\hline $\mathbf{L}_{\mathbf{V}} \mathbf{e p}\left(\mathbf{m m}^{-\mathbf{2}}\right)$ & $26 \pm 13$ & $68 \pm 20$ & 0.097 & 0.210 \\
\hline $\mathbf{A M D}(\boldsymbol{\mu m})$ & $18 \pm 2$ & $14 \pm 2$ & $\mathrm{NS}$ \\
\hline
\end{tabular}

All the quantitative parameters analyzed in both control (CTR) and prostate cancer (CA) specimens are expressed as mean \pm SEM. LI pcna: PCNA labeling index for endothelia cells. LI caspase 3: Caspase 3 labeling index for endothelial cells. $\mathrm{N}_{\mathrm{L}}$ : Number of endothelial cells x $10^{3}$ per mm of microvessel length. $\mathrm{L}_{\mathrm{V}}$ : length of microvessel per unit of volume of prostate stroma expressed in $\mathrm{mm}$ of microvessel per $\mathrm{mm}^{3}$ of stroma $\left(\mathrm{mm}^{-2}\right)$. $\mathrm{L}_{\mathrm{V}}$ ep: $\mathrm{L}_{\mathrm{V}}$ : length of microvessel per unit of volume of prostate epithelium expressed in mm of microvessel per $\mathrm{mm}^{3}$ of epithelium $\left(\mathrm{mm}^{-2}\right)$. AMD: Average mean diameter of microvessel expressed in $\mu \mathrm{m}$. P: significance level for the comparison between CTR and CA groups by the Student's t test $(\mathrm{p}<0.05)$. NS: not significant. S: significant.

findings agree with those obtained by other authors [17] also using the peri-tumor prostate area as a control.

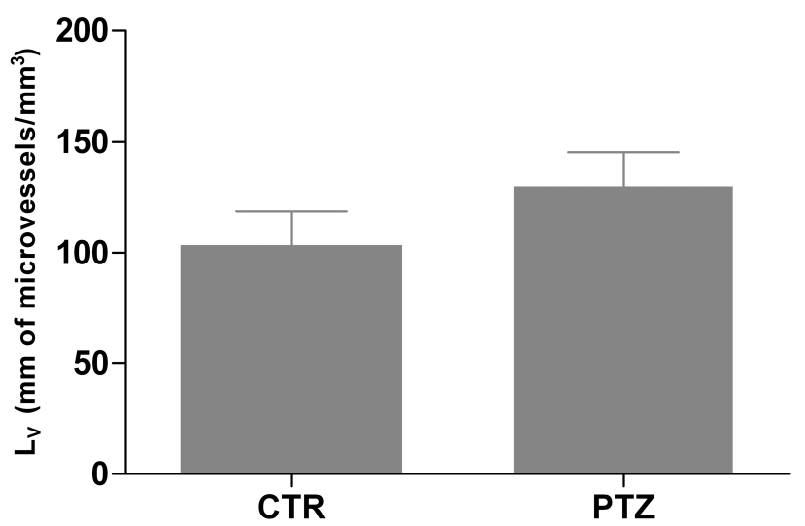

Fig. (3). Bar diagram for $L_{V}$ expressed as mean $\pm S E M$, in controls (CTR) and carcinoma-free area (PTZ) from CA group. No significant differences $(\mathrm{p}<0.05)$ were observed.

Nevertheless, it is worth noting that the $\mathrm{L}_{\mathrm{V}}$ from carcinoma-free areas in CA specimens tends to be higher than microvessel length density from CTR specimens (cases without cancer), which might be explained by the presence of local angiogenic factors secreted by cancer tissues and operating on the «normal » peri-tumor vessels. It is unclear how the microvascular bed enlarges in cancer cases more than in controls, without a significant increase of endothelial proliferation in the former. Several other authors also state the absence of relationship between endothelial proliferation and increase of microvessel density in both breast and prostate cancers [19, 26, 27]. A potential decrease of the apoptotic activity for the endothelium of prostate cancer might explain the increase of microvessel length without endothelial proliferation. It is known that the apoptosis of a relatively small proportion of endothelial cells is sufficient to mediate a significant decrease in microvessel density [28]. The resistance to apoptosis in cancer has been documented by several authors, who found decreased levels of the apoptotic-related enzymes, caspases 1 and 3, in tumor epithelium [5]. How- ever, in the present study, the endothelial apoptosis evaluated by quantification of the labeling index of endothelial cells caspase 3- immunoreactive was not diminished in the CA group in comparison with controls. Moreover, the decrease in the numerical density of the endothelial population in cancer does not support an increase of the survival of these cells. Thus, a "dilution" effect for the population of the endothelial cells, possibly due to the increase of microvessel length without endothelial proliferation, was proposed. The elongation of the cancer microvessels might be explained by the migration of endothelial cells [29] and the remodeling of the components of the capillary basal membrane [30]. Furthermore, the decrease in the amount of endothelial cells per unit of microvessel length, together with the increase of microvessel elongation, might render openings between endothelial cells, creating leaky vessels in cancer angiogenesis, as suggested by others [31, 32].

The stereological estimate of microvessel density as the length of microvessels per unit of volume of the reference space seems more accurate and unbiased than the generic term of microvessel density (MVD), usually employed in most of the studies revised $[13,14,33]$. There are two main reasons to prefer $L_{V}$ to MVD to quantify the size of the microvascular bed:

The first is that when MVD is employed, it is usual to identify MVD as the number of vessels per unit area. However, this is misleading, as it is not possible to count vessels in sections that are bidimensional planes (2D). Vessels are linear or tubular structures lying in a three dimensional space (3D). Actually, MVD estimates vessel profiles (i.e. sections of vessels), not whole vessels. In addition, when two closelying vessel sections are counted, the most probable result is that two sections from the same vessel, but not two different vessels, are registered. On the other hand, the number of profiles registered in a $2 \mathrm{D}$ plane of a linear feature that "lives" in a 3D space is, in fact, an estimate of the length of the linear structure, given by the expression: $2 \cdot$ (number of profiles counted) / area of the section. This is actually the length density $\left(\mathrm{L}_{\mathrm{V}}\right)$ of the linear structure [17]. The authors using MVD to estimate "number of vessels per unit of area" are underestimating the length density, because $L_{V}$ is equal to $2 \cdot \mathrm{MVD}$. 
The second reason for preferring $L_{V}$ is because, in MVD measurements, a systematic error of either plus-sampling or minus-sampling is introduced, as the "edge effect" of the reference frame (i.e. the microscopic field) is not taken into account. It would be erroneous to count or include all the profiles which intersect the reference frame. It would be equally erroneous to exclude all the boundary cases and count only those profiles lying entirely inside the frame. Plus-sampling overcounts the number of profiles per unit area, and introduces a sampling bias: larger profiles are more likely to be hit by the reference frame. Minus-sampling, on the other hand, undercounts the number of profiles per unit area, and introduces a sampling bias in favor of the smaller profiles [34].

In general, there are two remedies for sampling bias: we may either change the sampling rule to eliminate the bias, or we may correct the bias by reweighing the sampled items. In this study, the Sterio sampling rule was chosen [23], i.e., the disector, which is a reference frame with two inclusion borders and two exclusion borders. A profile is included in the count if: a) it is inside of the frame and does not touch any border or b) it is inside or outside of the frame but touches any of the inclusion borders and not any of the exclusion borders.

Another source of bias in MVD counts (as implemented in the majority of the studies analyzed) is the so-called "hotspot" sampling: selecting areas with an apparent (qualitative) greater density of profiles for counting. Some authors express a concern about this biased sampling. For example, Lissbrant et al., 1997 [35] state that "another concern has been the microvessel-counting technique. Therefore, we wanted to determine if counting hotspots promotes a bias, since this requires subjective selection of the most vascularized area. Possibly, it would be more accurate to use standard stereological techniques to measure the mean intratumoral volume density of microvessels in randomly chosen fields in each section". Why, then, in a number of studies $[15,16,35,36]$, was MVD relevant in order to quantitate angiogenesis? A possible explanation might be because the under-estimation of the vascular density resulting from the omission of factor $\mathrm{x} 2$ in the formula was balanced by the over-estimation resulting from the "hotspot" sampling.

In our study, the fields for estimation of $L_{V}$ were sampled by a systematic random sampling method: systematic sampling with a starting position which is random and uniformly distributed in the range of the object [34]. This method assures all of the fields scanned the same chance of being included in the measurements and is more efficient than the classic methods of uniform random sampling.

Although some authors indicate that the capillaries in prostate cancer have a wider lumen than in normal tissue [10], in the present study, no significant changes were observed in the average microvessel diameter in either group. Some authors have found that the highest proportion of microvessels near to the epithelium (touching capillaries) is seen in normal prostate, while the lowest is found in invasive adenocarcinoma [10]. This finding was also detected in the present study and could signify a poorer oxygen supply for cancer tissue than for normal prostate epithelium. However, the length density of capillaries per epithelial volume was found similar for both cancer and normal specimens, in ac- cordance with the rarity of tumor necrosis in prostate cancer, only observed in cancers with a primary Gleason pattern of 5 [37]. This similitude of vessel-epithelium correlation between normal prostate and cancer might suggest that the angiogenetic activity in prostate cancer is low in comparison with other types of tumors, which could contribute to the mild aggressiveness accounted for in most prostate cancers [38] stated in other studies [36]. Although microvessel density was not an independent prognostic predictor, according to the studies of some authors [39], it is reasonable to expect that cancers with more microvessel density show a more aggressive tumor phenotype.

\section{CONCLUSION}

Summarizing, we conclude that: a) The increase of angiogenetic activity in prostate carcinogenesis leads to an increment of microvascular length; b) The amount of endothelial cells per vascular length decreases in prostate cancer; c) There is no decrease of endothelial apoptosis in cancer microvessels; d) The increase of the length density of microvessels in prostate cancer is not directly associated with an enhancement of endothelial proliferation; and e) The blood supply of the epithelium was similar in both the cancerous and normal prostate.

\section{REFERENCES}

[1] American Cancer Society. Cancer Facts and Figures: Stastics for 2007. Atlanta 2007.

[2] Condon MS. The role of the stromal microenvironment in prostate cancer. Semin Cancer Biol 2005; 15: 132-7.

[3] D'Amore PA. Capillary growth: a two-cell system. Semin Cancer Biol 1992; 3: 49-56.

[4] Woo M, Hakem R, Soengas MS, et al. Essential contribution of caspase 3/CPP32 to apoptosis and its associated nuclear changes. Genes Dev 1998; 12: 806-19.

[5] Winter RN, Kramer A, Borkowski A, Kyprianou N. Loss of caspase- 1 and caspase- 3 protein expression in human prostate cancer. Cancer Res 2001; 61: 1227-32.

[6] O'Brien TS, Harris AL. Angiogenesis in urological malignancy. $\mathrm{Br}$ J Urol 1995; 76: 675-82.

[7] Folkman J. The role of angiogenesis in tumor growth. Semin Cancer Biol 1992; 3: 65-71.

[8] Montironi R, Galluzzi CM, Diamanti L, Taborro R, Scarpelli M, Pisani E. Prostatic intra-epithelial neoplasia. Qualitative and quantitative analyses of the blood capillary architecture on thin tissue sections. Pathol Res Pract 1993; 189: 542-8.

[9] Kong D, Li Y, Wang Z, Banerjee S, Sarkar FH. Inhibition of angiogenesis and invasion by 3,3'-diindolylmethane is mediated by the nuclear factor-kappaB downstream target genes MMP-9 and uPA that regulated bioavailability of vascular endothelial growth factor in prostate cancer. Cancer Res 2007; 67: 3310-19.

[10] Montironi R, Diamanti L, Thompson D, Bartels HG, Bartels PH Analysis of the capillary architecture in the precursors of prostate cancer: recent findings and new concepts. Eur Urol 1996; 30: 191200.

[11] Revelos K, Petraki C, Scorilas A, et al. Correlation of androgen receptor status, neuroendocrine differentiation and angiogenesis with time-to-biochemical failure after radical prostatectomy in clinically localized prostate cancer. Anticancer Res 2007; 27: 365160

[12] Sinha AA, Quast BJ, Reddy PK, et al. Microvessel density as a molecular marker for identifying high-grade prostatic intraepithelial neoplasia precursors to prostate cancer. Exp Mol Pathol 2004; 77: 153-9.

[13] Deering RE, Bigler SA, Brown M, Brawer MK. Microvascularity in benign prostatic hyperplasia. Prostate 1995; 26: 111-5.

[14] Bigler SA, Deering RE, Brawer MK. Comparison of microscopic vascularity in benign and malignant prostate tissue. Hum Pathol 1993; 24: 220-6. 
[15] Weidner N. Tumor angiogenesis: review of current applications in tumor prognostication. Semin Diagn Pathol 1993; 10: 302-13.

[16] Weidner N, Carroll PR, Flax J, Blumenfeld W, Folkman J. Tumor angiogenesis correlates with metastasis in invasive prostate carcinoma. Am J Pathol 1993; 143: 401-9.

[17] Mattfeldt T, Eckel S, Fleischer F, Schmidt V. Statistical analysis of reduced pair correlation functions of capillaries in the prostate gland. J Microsc 2006; 223: 107-19.

[18] Pallares J, Rojo F, Iriarte J, Morote J, Armadans LI, de Torres I. Study of microvessel density and the expression of the angiogenic factors VEGF, bFGF and the receptors Flt-1 and FLK-1 in benign, premalignant and malignant prostate tissues. Histol Histopathol 2006; 21: 857-65.

[19] Vartanian RK, Weidner N. Endothelial cell proliferation in prostatic carcinoma and prostatic hyperplasia: correlation with Gleason's score, microvessel density and epithelial cell proliferation. Lab Invest 1995; 73: 844-50.

[20] Baddeley A, Vedel Jensen E. Geometrical Probability. In: Baddeley A, Vedel JE, Eds. Stereology for Statisticians. Boca Raton: Chapman \& Hall 2005; pp. 111-33.

[21] Howard CV, Reed MG. Unbiased Stereology: Three-Dimensional Measurement in Microscopy. $2^{\text {nd }}$ ed. Oxford: Bios Scientific Publishers 2005.

[22] Martin JJ, Martin R, Codesal J, Fraile B, Paniagua R, Santamaria L. Cadmium chloride-induced dysplastic changes in the ventral rat prostate: an immunohistochemical and quantitative study. Prostate 2001; 46: 11-20.

[23] Sterio DC. The unbiased estimation of number and sizes of arbitrary particles using the disector. J Microsc 1984; 134: 127-36.

[24] Delves GH, Stewart AB, Cooper AJ, Lwaleed BA. Prostasomes, angiogenesis, and tissue factor. Semin Thromb Hemost 2007; 33: 75-9.

[25] Padhani AR, Harvey CJ, Cosgrove DO. Angiogenesis imaging in the management of prostate cancer. Nat Clin Pract Urol 2005; 2: 596-607.

[26] Fox SB, Gatter KC, Bicknell R, et al. Relationship of endothelial cell proliferation to tumor vascularity in human breast cancer. Cancer Res 1993; 53: 4161-3.

[27] Vartanian RK, Weidner N. Correlation of intratumoral endothelial cell proliferation with microvessel density (tumor angiogenesis) and tumor cell proliferation in breast carcinoma. Am J Pathol 1994; 144: 1188-94.

[28] Dong Z, Zeitlin BD, Song W, et al. Level of endothelial cell apoptosis required for a significant decrease in microvessel density. Exp Cell Res 2007; 313: 3645-57.

[29] Grizzi F, Russo C, Colombo P, et al. Quantitative evaluation and modeling of two-dimensional neovascular network complexity: the surface fractal dimension. BMC Cancer 2005; 5: 14.

[30] Carmeliet P. Angiogenesis in health and disease. Nat Med 2003; 9: 653-60.

[31] Hashizume H, Baluk P, Morikawa S, et al. Openings between defective endothelial cells explain tumor vessel leakiness. Am J Pathol 2000; 156: 1363-80.

[32] Terman BI, Stoletov KV. VEGF and tumor angiogenesis. Einstein Q J Biol Med 2001; 18: 59-66.

[33] Lekas A, Lazaris AC, Deliveliotis C, et al. The expression of hypoxia-inducible factor-1alpha (HIF-1alpha) and angiogenesis markers in hyperplastic and malignant prostate tissue. Anticancer Res 2006; 26: 2989-93.

[34] Baddeley A, Vedel Jensen E. Overview of Modern Stereology. In: Baddeley A, Vedel JE, Eds. Stereology for Statisticians. Boca Raton: Chapman \& Hall 2005; pp. 55-85.

[35] Lissbrant IF, Stattin P, Damber JE, Bergh A. Vascular density is a predictor of cancer-specific survival in prostatic carcinoma. Prostate 1997; 33: 38-45

[36] Bono AV, Celato N, Cova V, Salvadore M, Chinetti S, Novario R. Microvessel density in prostate carcinoma. Prostate Cancer Prostatic Dis 2002; 5: 123-7.

[37] Epstein JI, Allsbrook WC Jr, Amin MB, Egevad LL. The 2005 International Society of Urological Pathology (ISUP) Consensus Conference on Gleason Grading of Prostatic Carcinoma. Am J Surg Pathol 2005; 29: 1228-42.

[38] Abbas F, Scardino PT. The natural history of clinical prostate carcinoma. Cancer 1997; 80: 827-33.

[39] Arakawa A, Soh S, Chakraborty S, Scardino PT, Wheeler TM. Prognostic significance of angiogenesis in clinically localized prostate cancer (staining for Factor VIII-related antigen and CD34 Antigen). Prostate Cancer Prostatic Dis 1997; 1: 32-38.

(C) . Santamaría et al.; Licensee Bentham Open.

This is an open access article licensed under the terms of the Creative Commons Attribution Non-Commercial License (http://creativecommons.org/licenses/ by-nc/3.0/) which permits unrestricted, non-commercial use, distribution and reproduction in any medium, provided the work is properly cited. 